\title{
Free and Cellulose-bound Cellulases in a Cellulomonas Species
}

\author{
By PIERRE BÉGUIN* AND HARVEY EISEN \\ Département de Biologie Moléculaire, University of Geneva, \\ 30 Quai Ernest-Ansermet, CH-I2I I, Geneva 4, Switzerland \\ AND ANDRE ROUPAS \\ Service de Microbiologie Médicale, 22 Quai Ernest-Ansermet, \\ $\mathrm{CH}$-12I I, Geneva 4, Switzerland
}

(Received I4 December 1976; revised I 8 February 1977)

\begin{abstract}
A cellulolytic bacterium, identified as belonging to the genus Cellulomonas, produced two classes of cellulases when grown in the presence of cellulose. One class comprised enzymes which were tightly bound to cellulose, and the other, enzymes which were found free in the culture supernatant fluid. The cellulose-bound activity reached a maximum at the beginning of the stationary phase and then decreased, whereas the soluble activity increased to a plateau late in the stationary phase. The production of both classes of enzyme was repressed by adding cellobiose or glycerol to the cellulose. Deprivation of carbon sources did not induce cellulolytic activity. Cellobiose and sophorose showed only weak inducing activity in the absence of cellulose.
\end{abstract}

\section{INTRODUCTION}

The macromolecular and insoluble nature of cellulose suggests that it is degraded extracellularly by micro-organisms. The regulation of cellulase production by cellulolytic organisms must, therefore, occur without direct interaction between the substrate and intracellular effector molecules. Furthermore, the production of cellulases may be controlled at the level of secretion besides the more orthodox methods of control. Such control has been reported for Cellvibrio fulvus (Berg, 1975) and Pseudomonas fluorescens (Yamane et al., 1970, 197I) and might operate by: (i) induction by direct contact with cellulose, with cellulose presumably interacting with receptors located on the outside of the cell. (ii) Induction by degradation products of cellulose, on the assumption that low amounts of cellulase are always present outside the cell and yield soluble degradation products if cellulose is also present. A product, possibly cellobiose, could then penetrate the cell and act as a classical inducer. (iii) Inhibition of cellulase production by alternative carbon sources. In several systems, high concentrations of readily-assimilated carbon sources repress cellulase production. This catabolic-like repression has been demonstrated both in the presence and absence of an inducing substrate (Yamane et al., 1970; Lobanok \& Pavlovskaya, 1975; Berg, von Hofsten \& Pettersson, 1972; Mandels, 1975).

In the present work, a bacterium identified as a member of the genus Cellulomonas was found to produce two groups of extracellular cellulases, one group binding to cellulose and the other remaining free in the culture supernatant fluid. The production and regulation of production of these cellulases has been investigated by testing the effects of cellulose powder (a macromolecular substrate), cellobiose (a disaccharide derived from cellulose). glycerol (a readily-assimilated substrate, not related to cellulose) and acetate (a substrate

* Present address: Department of Neurobiology, Stanford University School of Medicine, Stanford Medical Center, Stanford, California 94305, U.S.A. 
allowing only poor growth) on extracellular cellulolytic activity. The effect of sophorose was also examined since it is an active inducer in Pseudomonas fluorescens (Yamane et al., 1970) and Trichoderma viride (Mandels, Parrish \& Reese, 1962).

\section{METHODS}

Organisms and growth. The cellulolytic isolate, IIbc, was a gift from Dr M. Ibarra, University of Havana, Cuba. Cellulomonas flavigena NCTC7547 (ATCC484) was obtained from the National Collection of Type Cultures, London, where it is listed as Corynebacterium fimi. The isolate was grown routinely at $37^{\circ} \mathrm{C}$ in $\mathrm{L}$ broth, tryptone broth or M9 mineral medium (Miller, 1972) supplemented with $2 \mu \mathrm{g}$ biotin $\mathrm{ml}^{-1}$, I $\mu \mathrm{g}$ vitamin $\mathrm{B}_{1} \mathrm{ml}^{-1}$ and either $0.5 \%$ glycerol, $0.2 \%$ glucose, $0.2 \%$ cellobiose or $2.5 \%$ cellulose powder (all $\left.\mathrm{w} / \mathrm{v}\right)$.

Taxonomic tests. The biochemical and morphological properties of the two strains were compared according to Lenette, Spaulding \& Truand (1974). Acid production from various carbohydrates ( $\%$, w/v, freshly prepared) was tested in cystine trypticase agar medium. When possible, results were confirmed using the API 50 kit (API International). All tests were performed at $30^{\circ} \mathrm{C}$, except motility which was examined at $22^{\circ} \mathrm{C}$.

Growth rate. The generation time of strain IIbc growing on $0.435 \%(\mathrm{v} / \mathrm{v})$ glycerol, $0.2 \%$ glucose, $0.2 \%$ cellobiose, $1 \%$ CM-cellulose, $2.5 \%$ cellulose powder (all w/v) or $50 \mathrm{~mm}$-sodium acetate was determined by following the absorbance of cultures at $600 \mathrm{~nm}$. Cellulose-grown cultures were first centrifuged for $12 \mathrm{~s}$ at $650 \mathrm{~g}$ to remove the cellulose. Absorbance values were multiplied by $0.1 \mathrm{mg} \mathrm{ml}^{-1} E_{600}{ }^{-1}$ to give $\mathrm{mg}$ cell protein $\mathrm{ml}^{-1}$ : this conversion factor was calculated from the protein content of bacterial suspensions [assayed according to Lowry et al. (195I), using bovine serum albumin as standard] after heating with toluene at $100^{\circ} \mathrm{C}$ for $5 \mathrm{~min}$.

Assay of free cellulase activity. Cultures were centrifuged at $1900 \mathrm{~g}$ for $10 \mathrm{~min}$ and samples of the

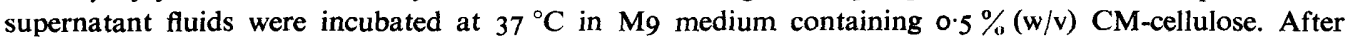
6 to $150 \mathrm{~min}$, the reaction was stopped by heating at $100^{\circ} \mathrm{C}$ for $10 \mathrm{~min}$. The number of reducing sugar termini, created by hydrolysis of the CM-cellulose, was measured according to Somogyi (1952). The precipitate that appeared after adding the Nelson reagent (Nelson, 1944) was sedimented before measuring $E_{600}$. One unit was defined as the amount of enzyme that produced reducing sugars equivalent to I $\mu \mathrm{g}$ glucose $\mathrm{h}^{-1}$.

Assay of cellulose-bound activity. The cellulose collected from centrifuged culture medium ( I $\mathrm{s}$ at $650 \mathrm{~g}$ ) was washed three or four times by decanting in an ice-cold buffer solution (BU) containing $44 \mathrm{mM}-\mathrm{Na}_{2} \mathrm{HPO}_{4}$, $68 \mathrm{~mm}-\mathrm{NaCl}, 22 \mathrm{~mm}-\mathrm{KH}_{2} \mathrm{PO}_{4}$ and $0.5 \mathrm{~mm}-\mathrm{MgSO}_{4}$. This removed free enzymes and most of the remaining bacteria. Samples $\left(50 \mathrm{mg}\right.$ ) of the drained paste were incubated for 6 to $150 \mathrm{~min}$ at $37^{\circ} \mathrm{C}$ in I $\mathrm{ml} \mathrm{Mg}$ medium containing $\mathrm{r} \%(\mathrm{w} / \mathrm{v}) \mathrm{CM}$-cellulose. The reaction was stopped by heating at $100^{\circ} \mathrm{C}$ for $10 \mathrm{~min}$, the cellulose was removed by centrifuging and $0.5 \mathrm{ml}$ of the supernatant fluid was assayed for reducing sugars. The weight of cellulose in the paste was determined from the dry wt of an identical sample. The activity was expressed in units ( $\mathrm{g}$ cellulose $)^{-1}$ and converted into units ( $\left.\mathrm{ml} \mathrm{culture}\right)^{-1}$ or units (mg cell protein) ${ }^{-1}$.

Contribution of residual bacteria to free and cellulose-bound activities. The cellulolytic activity bound to residual bacteria was estimated by multiplying the absorbance of bacteria present in the assay by the specific activity bound to centrifuged bacteria. The maximum amount of residual bacteria in washed cellulose was estimated from the amount of protein that could be extracted from the cellulose by heating for $5 \mathrm{~min}$ at $100{ }^{\circ} \mathrm{C}$ with Io $\mathrm{mm}$-Tris $/ \mathrm{HCl}$ containing $\mathrm{I} \%(\mathrm{w} / \mathrm{v})$ sodium dodecyl sulphate.

Influence of carbon source and stage of culture growth on cellulase production. Bacteria were grown with shaking at $37^{\circ} \mathrm{C}$ either in $800 \mathrm{ml} \mathrm{M9} \mathrm{medium} \mathrm{supplemented} \mathrm{with} \mathrm{cellulose} \mathrm{alone} \mathrm{or} \mathrm{in} 80 \mathrm{ml}$ M9 medium supplemented with other combinations of substrates. Growth, free activity and cellulose-bound activity were followed up to the stationary phase by taking $3 \mathrm{ml}$ samples which were chilled and immediately assayed. The culture containing cellulose and cellobiose was followed only until the late-exponential phase, when cellobiose could no longer be detected in the medium by the reducing sugar assay.

To test the effects of low substrate concentrations, bacteria growing exponentially in M9 medium containing $0.435 \%$ glycerol or in L broth containing $0.2 \%$ glucose were centrifuged, washed in BU buffer and resuspended at a density corresponding to $0.2 \mathrm{mg}$ protein $\mathrm{ml}^{-1}\left(0 \cdot 1 \mathrm{mg} \mathrm{ml}{ }^{-1}\right.$ for resuspension media containing sophorose) in $10 \mathrm{ml} \mathrm{M9}$ medium containing the following carbon sources: (i) no substrate; (ii) $0.01,0.02,0.05,0.1$ or $0.2 \%(\mathrm{w} / \mathrm{v})$ cellobiose; (iii) $0.0087,0.0174,0.0435$ or $0.174 \%(\mathrm{v} / \mathrm{v})$ glycerol; (iv) $0.0002,0.00066,0.002,0.0066,0.02$ or $0.066 \%(\mathrm{w} / \mathrm{v})$ sophorose; (v) $2.5 \%(\mathrm{w} / \mathrm{v})$ cellulose. The suspensions were incubated with shaking at $37^{\circ} \mathrm{C}$ for 20 to $23 \mathrm{~h}$ and assayed for bacterial density and extracellular cellulase activity. The latter was determined in the supernatant fluid after centrifuging the bacteria from cultures that did not contain cellulose. The supernatant fluids from the cultures containing 0.02 and $0.066 \%$ sophorose were dialysed at $4{ }^{\circ} \mathrm{C}$ against $\mathrm{Mg}$ medium with no added carbon source before assaying cellulase 
activity. For cultures containing cellulose, the total (free and cellulose-bound) extracellular cellulase activity was determined.

Chemicals. Cellulose CF II was purchased from Whatman; carboxymethylcellulose (CM-cellulose) from Fluka, Buchs, Switzerland; sophorose from Roth, Karlsruhe, W. Germany; cellobiose and other carbohydrates from Calbiochem; cyclic AMP from Sigma; agar, tryptone and yeast extract from Difco; and cystine trypticase agar from BBL. All other chemicals were of the purest grade commercially available.

\section{RESULTS}

\section{Identification of strain IIbc}

Strain IIbc and Cellulomonas flavigena NCTC7547 were coryneform, Gram-variable rods which formed yellow glistening colonies on agar media; liquefied gelatin slowly; reduced nitrate; degraded filter paper; produced neither acetylmethylcarbinol nor indole; hydrolysed starch and aesculin; and produced catalase, oxidase, $\beta$-galactosidase and DNAase but no urease, ornithine decarboxylase, arginine dihydrolase or lysine decarboxylase. They produced acid from glucose, glycerol, L-arabinose, D-xylose, galactose, fructose, mannose, maltose, trehalose, cellobiose, amygdalin, arbutin and salicin but not from erythritol, adonitol, dulcitol, mannitol, meso-inositol, sorbitol, D-arabinose, ribose, L-xylose, sorbose and inulin. Biotin and thiamin were required by strain IIbc (NCTC7547 was not tested). Strain IIbc was non-motile, failed to produce acid from lactose, rhamnose, melibiose and melezitose, but did so from raffinose; whereas NCTC7547 gave the opposite results. On the basis of the above characters, we concluded that strain IIbc belongs to the genus Cellulomonas. Our diagnosis is supported by comparison of the properties of strain IIbc with those described elsewhere for members of this genus (Buchanan \& Gibbons, 1974; Han \& Srinivasan, 1968; Kaufmann et al., 1976). Cellulomonas flavigena is now the only recognized species, although some minor differences in motility, chromogenesis, nitrate reduction or carbon source utilization might occur between different strains (Buchanan \& Gibbons, 1974).

\section{Examination of cellulase activity}

The growth rate in M9 mineral medium was highest with glucose, cellobiose or glycerol as carbon source (generation time, I90 $\mathrm{min}$ ). Growth on cellulose (generation time, 400 to $450 \mathrm{~min}$ ) or even CM-cellulose (generation time, $240 \mathrm{~min}$ ) was much slower, probably because the hydrolysis of cellulose was rate-limiting. Growth on acetate was poor (generation time, 700 to $800 \mathrm{~min}$ ).

Bacteria growing exponentially in the presence of cellulose produced 300 units of cellulase (mg cell protein) $)^{-1}$. Thus the highest possible contribution of residual bacteria was 300 units (g cellulose) $)^{-1}\left(7.5\right.$ units $\mathrm{ml}^{-1}$ in cultures containing $2.5 \%$ cellulose) to the cellulose-bound activity and $\mathrm{I}$ unit $\mathrm{ml}^{-1}$ to the free activity.

Of the cellulolytic activity that remained after washing the cellulose pellet from a cellulose-grown culture three times with BU buffer, $93 \%$ was still recovered after a fourth wash with the same buffer, indicating that the enzyme was tightly bound to its substrate. The activity was detached from the cellulose during incubation with CM-cellulose, as hydrolysis of CM-cellulose continued after the cellulose had been removed. The activity bound to cellulose could be eluted with guanidine hydrochloride followed by dialysis of the extract (Béguin \& Eisen, unpublished results).

During growth of $C$. flavigena (strain IIbc) on cellulose, the cellulose-bound cellulases appeared first, reaching a maximum at the end of the exponential phase and then decreasing markedly during the stationary phase (Fig. I). Free cellulases appeared at the end of the exponential phase and during the stationary phase and remained active for much longer than the cellulose-bound cellulases.

Glycerol and cellobiose repressed cellulolytic activity when added to cultures growing on cellulose (Table I); cyclic AMP ( $\mathrm{mM}$ ) did not reverse this repression. Acetate, on 


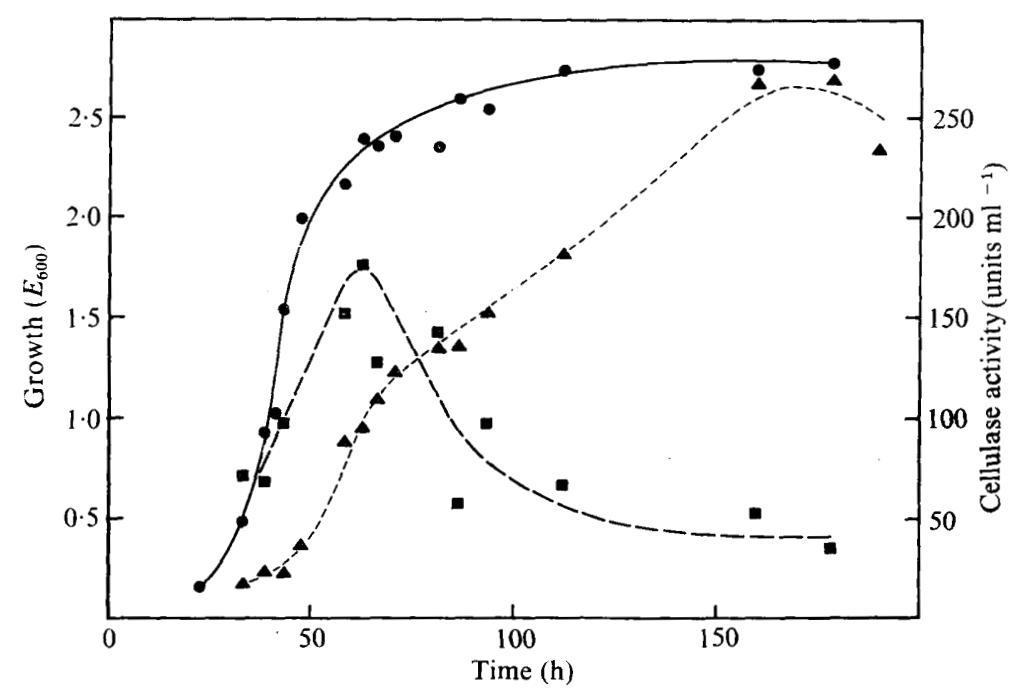

Fig. I. Bacterial growth $\left(E_{600} ; \ominus\right)$, cellulose-bound cellulase activity $(\boldsymbol{\sigma})$ and free cellulase activity $(\boldsymbol{\Delta})$ in a cellulose-grown culture.

Table I. Induction of cellulase activities by cellulose and repression by glycerol and cellobiose

\begin{tabular}{|c|c|c|c|c|}
\hline \multirow[b]{2}{*}{ Carbon source } & \multicolumn{2}{|c|}{$\begin{array}{l}\text { Maximum cellulose-bound } \\
\text { activity }\end{array}$} & \multicolumn{2}{|c|}{$\begin{array}{l}\text { Maximum soluble } \\
\text { activity }\end{array}$} \\
\hline & units $\mathrm{ml}^{-1}$ & $\begin{array}{c}\text { units } \\
(\mathrm{mg} \text { protein })^{-1}\end{array}$ & units $\mathrm{ml}^{-1}$ & $\begin{array}{c}\text { units } \\
(\mathrm{mg} \text { protein })^{-1}\end{array}$ \\
\hline ose $(2.5 \%, w / v)$ & 250 & $12 \cdot 5$ & 160 & $4 \cdot 8$ \\
\hline & - & - & $<10$ & $<0.8$ \\
\hline $\begin{array}{l}\operatorname{lse}(2.5 \%, w / v)+ \\
\operatorname{siose}(0.2 \%, w / v)\end{array}$ & 25 & 0.55 & 30 & 0.65 \\
\hline $\begin{array}{l}\text { ose }(2.5 \%, w / v)+ \\
\text { rol }(0.435 \%, v / v)\end{array}$ & 25 & $\mathrm{I} \cdot 55$ & 15 & 0.53 \\
\hline $\begin{array}{l}\text { se }(2.5 \%, w / v)+ \\
\text { te }(50 \mathrm{mM})\end{array}$ & I 55 & $9 \cdot 0$ & 160 & $6 \cdot 7$ \\
\hline$(50 \mathrm{~mm})$ & - & - & $<\mathrm{IO}$ & $<0.5$ \\
\hline
\end{tabular}

which the bacterium grows only very slowly, did not affect cellulolytic activity significantly when added together with cellulose. No detectable cellulase activity was found in cultures deprived of carbon source or growing on acetate (a non-repressing substrate) (Table I), demonstrating that very little, if any, enzyme is made constitutively, even if there is no catabolic repression.

The specific activity of cellulase in cultures incubated with suboptimal amounts of glycerol, cellobiose or sophorose was always at least 14 times lower than the activity in similar cultures incubated with cellulose [ $14^{\cdot} 9$ units (mg protein) $\left.{ }^{-1}\right]$. However, the activity of cellulase in cultures incubated with 0.02 to $0.2 \%$ cellobiose [ $\mathrm{I} \cdot \mathrm{OI}$ units (mg protein)-1 with $0.05 \%$ cellobiose] was about twice that in cultures incubated with similar concentrations of glycerol [0.52 units (mg protein) ${ }^{-1}$ with $0.0435 \%$ glycerol]. Sophorose, which in Trichoderma viride induces cellulase at concentrations 2500 times lower than cellobiose (Mandels et al., 1962) was, at best, equivalent to cellobiose in inducing cellulase activity in Cellulomonas [0.84 units (mg protein) ${ }^{-1}$ with $0.066 \%$ sophorose]. 


\section{DISCUSSION}

The binding of cellulases to their substrates is of obvious advantage to prevent them being washed away in the soil where Cellulomonas flavigena is found. Affinity of cellulase for cellulose has been reported for Cytophaga (Marshall, 1973) and Trichoderma viride (Berghem, Pettersson \& Axiö-Frederiksson, 1976). The varying ratio between free and cellulose-bound activity as the culture reaches the stationary phase could be caused by existing enzymes being modified or by new types of enzymes being produced. Cellulose itself could also be modified in a way that reduces the binding constant. The delayed appearance of activity in the supernatant fluid might also be explained if both types of enzymes could bind to cellulose, so that free activity only appears after all the binding sites on the cellulose have been occupied. However, additional assumptions must then be made to account for the decrease in cellulose-bound activity during the stationary phase.

Extracellular cellulase production by Cellulomonas is subject to repression by readilyassimilated carbon sources, as has been reported for other bacteria and fungi (Berg et al., 1972; Mandels, 1975; Yamane et al., 1970). However we find it difficult to believe that this repression is the only mechanism involved in cellulase regulation in Cellulomonas. The failure to detect cellulase in cultures deprived of carbon sources or grown on a nonrepressing substrate like acetate argues strongly that an inducer is required for high level expression of cellulase, although the detailed mechanism of induction remains to be defined. Under our conditions, cellulose was a much more powerful inducer than any other carbon source. This does not imply, however, that cellulose induces directly (e.g. by binding to a receptor on the cell surface). That degradation products like cellobiose may be the true inducers is supported by the observation that cellulolytic activity in cellobiosegrown cultures was twice that in glycerol-grown cultures. The weak induction observed with low concentrations of sophorose indicates that this disaccharide, which could arise from oligosaccharides derived from cellulose by transglycosylation, is a much weaker inducer in Cellulomonas than in Trichoderma viride (Mandels et al., I962).

The weak inducing power of cellobiose (and presumably sophorose) is probably due to catabolic repression, an effect which has long been known to counteract the inducing activity of cellobiose in Trichoderma viride (Mandels \& Reese, I960). More recently, Stewart \& Leatherwood (1976) observed the same phenomenon with another Cellulomonas isolate, and showed that in mutants insensitive to catabolic repression, cellobiose and sophorose were good inducers of cellulolytic activity.

The experiments described in this paper deal only with extracellular cellulases. We did not investigate the regulation of cellulolytic activity present either on the outside of the cell membrane (i.e. demonstrable on intact cells), or in the cytoplasm (i.e. demonstrable only after disrupting the cells). Control of these activities may well be different from that of the extracellular activity, as is the case for Pseudomonas fluorescens (Yamane et al., 1970, 1971) and Cellvibrio fulvus (Berg, 1975).

We wish to thank Dr M. Ibarra and the members of the Department of Biology, University of Havana, for providing us with strain IIbc and for their hospitality to H.E. We are also grateful to Drs G. Selzer and C. Georgopoulos for reading and commenting on the manuscript. This work was supported by grant no. 3.519 .75 from the Fonds National Suisse de la Recherche Scientifique. 


\section{REFERENCES}

Berg, B. (1975). Cellulase location in Cellvibrio fulvus. CanadianJournal of Microbiology 21, $5 \mathrm{I}-57$.

Berg, B., von Hofsten, B. \& Pettersson, G. (1972). Growth and cellulase formation by Cellvibrio fulvus. Journal of Applied Microbiology 35, 20I204.

Berghem, L. E. R., Pettersson, L. G. \& AxiöFrederIKSSON, U. B. (1976). The mechanism of enzymatic cellulose degradation: purification and properties of two different $1,4-\beta$-glucanohydrolases from Trichoderma viride. European Journal of Biochemistry 61, 62 I-630.

Buchanan, R. E. \& Gibbons, N. E. (editors) (1974). Bergey's Manual of Determinative Bacteriology, 8th edn. Baltimore: Williams \& Wilkins.

Han, Y. W. \& SRInivasan, V. R. (I968). Isolation and characterization of a cellulose-utilizing bacterium. Applied Microbiology 16, 1 140-1 145.

Kaufmann, A., Fegan, J., Doleac, P., Gainer, C., WITTICH, D. \& GLANN, A. (1976). Identification and characterization of a cellulolytic isolate. Journal of General Microbiology 94, 405-408.

Lenette, E. H., Spaulding, E. H. \& Truand, J. P. (editors) (1974). Manual of Clinical Microbiology, and edn. Washington, D.C.: American Society for Microbiology.

Lobanok, A. G. \& Pavlovskaya, Zh. I. (1975). Derepression of cellulase synthesis in Trichoderma lignorum during limited consumption of readily assimilated carbon sources. Microbiology (Mikrobiologiya) 44, 25-28.

Lowry, O. H., Rosebrough, N. J., Farr, A. L. \& RaNDALl, R. J. (r95I). Protein measurement with the Folin phenol reagent. Journal of Biological Chemistry I93, 265-275.
MANDELS, M. (1975). Microbial sources of cellulases. Biotechnology and Bioengineering Symposium 5, 81-105.

Mandels, M. \& Reese, E. T. (1960). Induction of cellulase in fungi by cellobiose. Journal of Bacteriology 79, 816-826.

Mandels, M., Parrish, F. W. \& Reese, E. T. (1962). Sophorose as an inducer of cellulase in Trichoderma viride. Journal of Bacteriology 83, 400-407.

Marshall, J. J. (1973). Behavior of $\beta$-glucan hydrolases on ion exchangers. Analytical Biochemistry 53, $19 \mathrm{I}-198$.

Miller, J. H. (1972). Experiments in Molecular Genetics, pp. $43^{1-433}$. New York: Cold Spring Harbor Laboratory.

Nelson, N. (1944). A photometric adaptation of the Somogyi method for the determination of glucose. Journal of Biological Chemistry 153, 375380.

Stewart, B. J. \& Leatherwood, J. M. (I976). Derepressed synthesis of cellulase by Cellulomonas. Journal of Bacteriology 128, 609-615.

Somogyi, M. (1952). Notes on sugar determination. Journal of Biological Chemistry 195, 19-23.

Yamane, K., Suzuki, H., Hirotani, M., Ozawa, H. \& Nisizama, K. (1970). Effect of nature and supply of carbon source on cellulase formation in Pseudomonas fluorescens var. cellulosa. Journal of Biochemistry, Tokyo 67, 9-18.

Yamane, K., Yoshikawa, T., Suzuki, H. \& NisizawA, K. (1971). Localization of cellulase components in Pseudomonas fluorescens var. cellulosa. Journal of Biochemistry, Tokyo 69, $77 \mathrm{I}-780$. 